\title{
BMJ Open Effect of regional versus general anaesthesia on postoperative delirium in elderly patients undergoing surgery for hip fracture: a systematic review
}

\author{
Vanisha Patel, ${ }^{1}$ Rita Champaneria, ${ }^{2}$ Janine Dretzke, ${ }^{3}$ Joyce Yeung ${ }^{4,5}$
}

To cite: Patel V, Champaneria R, Dretzke J, et al. Effect of regional versus general anaesthesia on postoperative delirium in elderly patients undergoing surgery for hip fracture: a systematic review. BMJ Open 2018;8:e020757. doi:10.1136/ bmjopen-2017-020757

\section{- Prepublication history and} additional material for this paper are available online. To view these files, please visit the journal online (http://dx.doi. org/10.1136/bmjopen-2017020757).

Received 23 November 2017 Revised 17 October 2018 Accepted 26 October 2018
Check for updates

(C) Author(s) (or their employer(s)) 2018. Re-use permitted under CC BY-NC. No commercial re-use. See rights and permissions. Published by BMJ.

For numbered affiliations see end of article.

Correspondence to Dr Joyce Yeung; j.yeung.4@warwick.ac.uk

\section{ABSTRACT}

Objective Older patients with hip fractures who are undergoing surgery are at high risk of significant mortality and morbidity including postoperative delirium. It is unclear whether different types of anaesthesia may reduce the incidence of postoperative delirium. This systematic review will investigate the impact of anaesthetic technique on postoperative delirium. Other outcomes included mortality, length of stay, complications and functional outcomes.

Design Systematic review of randomised controlled trials and non-randomised controlled studies.

Data sources Bibliographic databases were searched from inception to June 2018. Web of Science and ZETOC databases were searched for conference proceedings. Reference lists of relevant articles were checked, and clinical trial registers were searched to identify ongoing trials.

Eligibility criteria Studies were eligible if general and regional anaesthesia were compared in patients (aged 60 and over) undergoing hip fracture surgery, reporting primary outcome of postoperative delirium and secondary outcomes of mortality, length of hospital stay, adverse events, functional outcomes, discharge location and quality of life. Exclusion criteria were anaesthetic technique or drug not considered current standard practice; patients undergoing hip fracture surgery alongside other surgery and uncontrolled studies.

Results One hundred and four studies were included. There was no evidence to suggest that anaesthesia type influences postoperative delirium or mortality. Some studies suggested a small reduction in length of hospital stay with regional anaesthesia. There was some evidence to suggest that respiratory complications and intraoperative hypotension were more common with general anaesthesia. Heterogeneity precluded metaanalysis. All findings were described narratively and data were presented where possible in forest plots for illustrative purposes.

Conclusions While there was no evidence to suggest that anaesthesia types influence postoperative delirium, the evidence base is lacking. There is a need to ascertain the impact of type of anaesthesia on outcomes with an adequately powered, methodologically rigorous study.

PROSPERO registration number CRD42015020166.

\section{Strengths and limitations of this study}

- This systematic review provides an update to evidence that examines whether the type of anaesthesia affects the development of postoperative delirium in patients with hip fractures.

- The review included randomised and non-randomised studies that included one or more types of regional versus one or more types of general anaesthesia provided they are in current use as described in the UK.

- Other outcomes were mortality, length of hospital stay, adverse events, functional outcomes, discharge location and quality of life.

\section{INTRODUCTION}

There are an estimated 70 000-75 000 hip fractures in the UK each year with an annual cost of $£ 2$ billion. ${ }^{1}$ This is projected to rise and reach 100000 patients a year and costing $£ 3.6-5.6$ billion by $2033 .^{2}$

Patients undergoing hip fracture surgery are often frail with intercurrent illness ${ }^{3}$ and are at risk of mortality and significant morbidity. In 2014, the National Hip Fracture Database reported 30-day mortality as $7.5 \%{ }^{4}$ Following surgery, adverse outcomes can include delirium, myocardial infarction, pneumonia and cerebrovascular accident. ${ }^{5}$

Delirium is a common neuropsychiatric syndrome defined in the Diagnostic and Statistical Manual of Mental Disorders, 5th edition (DSM-V) as the disturbance of attention, awareness and cognition which develops over a short period of time, represents a change from baseline and tends to fluctuate during the course of the day. ${ }^{67}$ Postoperative delirium has been reported to affect between $32 \%$ and $53.3 \%$ of patients and is associated with prolonged hospital stay, discharge to care homes, difficulty in regaining function in activities of daily living and increased risk of development of cognitive dysfunction and 
dementia in the future. ${ }^{8-13}$ The aetiology of delirium is multifactorial, with both modifiable and non-modifiable risk factors. ${ }^{14} 15$ There is no known treatment for delirium; however, a careful approach in the perioperative period may reduce its incidence and severity. ${ }^{6915-18}$ Guideline committees have cautiously recommended that regional anaesthesia should be given unless contraindicated. ${ }^{1919}$ Despite this, the type of anaesthesia administered in patients with hip fractures remains varied. ${ }^{4}$

Ninety-eight per cent of patients with hip fracture are offered surgery and will require anaesthesia. ${ }^{5}$ Anaesthesia can be broadly classified into general (GA) or regional anaesthesia (RA). RA uses neuraxial blocks that avoid the use of GA drugs and opiates which have been linked to postoperative delirium. ${ }^{3}$ Excessive depth of anaesthesia and perioperative hypotension have been reported in GA patients and are both associated with an increased risk of mortality. ${ }^{20}$ However, the risk of perioperative hypotension and sedation is not completely eradicated with RA. ${ }^{21} 22$

Findings from previous systematic reviews looking at the effects of type of anaesthesia on postoperative outcomes in patients with hip fracture are broadly suggestive of improved outcomes ${ }^{352324}$ and reduced incidence of postoperative delirium in patients having RA. ${ }^{35222526}$ However, some studies included in these reviews reported use of outdated anaesthetic drugs that are no longer relevant to current clinical practice. ${ }^{524}$ Further limitations were the inclusion of only randomised controlled trials, ${ }^{352324}$ lack of focus on delirium as a primary outcome, ${ }^{3522} 2426$ a limited search strategy ${ }^{22}$ and restrictive selection criteria (eg, exclusion of studies with patients with cognitive impairment). ${ }^{2325} 26$ Inadequate exploration of heterogeneity relating to delirium assessment and rating scales and assessment time points was also common. This systematic review aims to provide an up-to-date, comprehensive and methodologically robust analysis to examine the effect of RA versus GA on postoperative delirium and other outcomes in older patients undergoing surgery for hip fracture.

\section{METHODS}

The protocol for this systematic review has been published and is registered with PROSPERO (CRD42015020166). ${ }^{27}$ A summary of the methods is outlined below. Reporting of the systematic review was in accordance with the Preferred Reporting Items for Systematic Reviews and Meta-Analyses guidelines. ${ }^{28}$

\section{Search strategy and selection criteria}

Bibliographic databases (Embase, MEDLINE, CINAHL and the Cochrane Library (CENTRAL)) were searched from inception to June 2018 using a combination of index terms and keywords relating to the population, intervention and comparator (see online supplementary appendix A for sample search strategy). There was no restriction by search date, study design or language.
Web of Science and ZETOC databases were searched for conference proceedings. Reference lists of relevant articles were checked, and clinical trial registers ( www.clinicaltrials.gov, www.isrctn.com and http://www. who.int/ictrp/en/) were searched to identify ongoing trials (online supplementary appendix B). Endnote V.7 (Thomson Reuters) was used to store records and facilitate screening.

\section{Study selection}

Studies were eligible for inclusion if they met the following predefined criteria:

1. Population-patients aged $\geq 60$ years (or with a majority $\geq 60$ ) undergoing surgery for fragility hip fracture.

2. Intervention and comparator-one or more types of regional versus one or more types of general anaesthesia provided they are in current use as described in the $\mathrm{UK}^{19}$

3. Outcomes-primary outcome: postoperative delirium (any criteria as defined by study authors); secondary outcomes: mortality, length of hospital stay, adverse events, functional outcomes, discharge location and quality of life.

4. Randomised or non-randomised controlled studies (prospective or retrospective).

Exclusion criteria for the primary outcome of 'postoperative delirium' were anaesthetic technique or drug not considered current standard practice (eg, outdated anaesthetic agents-halothane, enflurane, xenon); patients undergoing hip fracture surgery alongside other surgery (eg, multiple trauma injuries); uncontrolled studies. Two reviewers (RC, VP) independently screened titles and abstracts. Any disagreements were resolved with the support of JY. Reasons for exclusion were recorded at the full text stage.

\section{Data extraction and quality assessment}

A piloted, standardised data extraction form was used to record information on study design, patient characteristics, type of surgery, anaesthesia type and outcomes. The Cochrane Collaboration risk of bias tool ${ }^{29}$ was used to assess the methodological quality of randomised controlled trials and the Newcastle-Ottawa scale ${ }^{30}$ for non-randomised studies. Full translations could not be obtained for three included studies ${ }^{31-33}$; extracted data are therefore based mainly on numerical data and the English abstract. Data was extracted by RC and VP, with data checking by JY (for RC) and JD (for VP).

\section{Data analysis and synthesis}

Findings were grouped according to outcome. Where there was sufficient data, results were presented in forest plots (delirium, mortality and length of hospital stay). Results for studies not included in the forest plot were reported narratively. Effect estimates were not pooled as clinical and methodological heterogeneity was considered to be too great. Forest plots were thus used for illustrative purposes only and potential sources of heterogeneity 
(such as study design or timing of assessment) have been highlighted. Where studies did not report sufficient data for inclusion into a forest plot (eg, results reported narratively only, or a $p$ value only stated) results or conclusions from the study were nonetheless described in order to report the totality of the available evidence. Occurrence of delirium and mortality were reported as relative risks or ORs; length of stay (days) was reported as a mean difference. Adverse events were tabulated, where possible, according to the postoperative morbidity survey (POMS) criteria. ${ }^{34}$ Findings for other outcomes (functional outcomes, quality of life and discharge location) were reported narratively as heterogeneity and/or a paucity of data precluded representation in forest plots. Formal sensitivity analysis according to study quality, and assessment of publication bias using funnel plots were not possible.

\section{Patient and public involvement}

This systematic review is part of a programme of research looking at impact of anaesthesia on postoperative delirium. The research programme has received input from patient partner and Clinical Research Ambassador Group at Heart of England National Health Service Foundation Trust.

\section{RESULTS}

Of 4859 citations screened, 104 studies met the eligibility criteria (figure 1). There were 7 randomised controlled trials (RCTs), 34 prospective and 63 retrospective controlled studies.

Twenty-two studies reported delirium (5 RCTs, ${ }^{35-39}$ 9 prospective e $^{18} 40-47$ and 8 retrospective studies $\left.{ }^{48-55}\right) ; 58$ studies reported mortality (2 RCTs, ${ }^{3538} 12$ prospective ${ }^{42} 45$

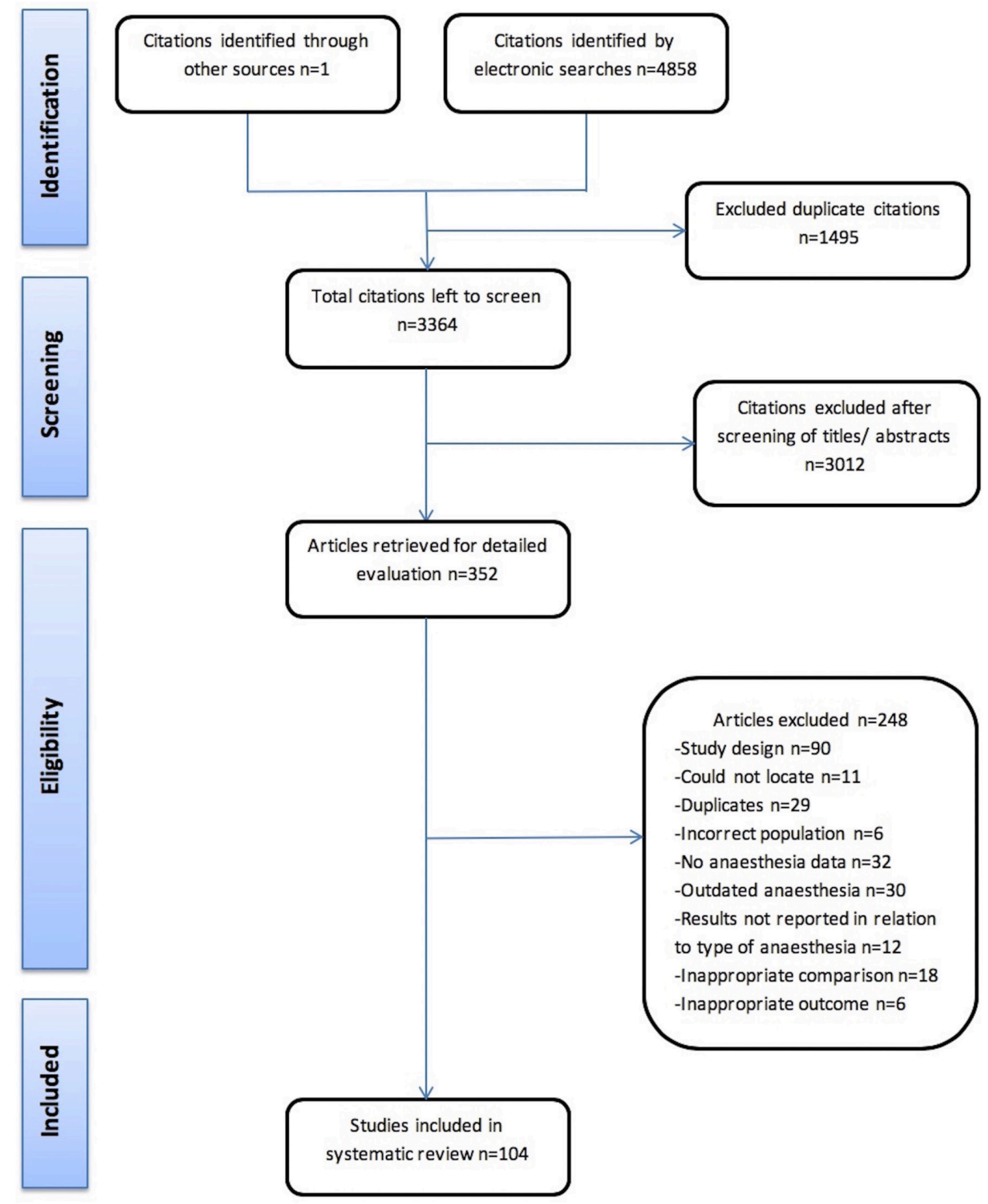

Figure 1 Preferred Reporting Items for Systematic Reviews and Meta-Analyses (PRISMA) flow diagram. The PRISMA diagram details our search and selection process applied during the review. 
56-65 and 44 retrospective studies $4202131324851525466-100$ ); 25 studies reported length of hospital stay (2 RCTs, ${ }^{36}{ }^{38} 6$ prospective $^{424558101-103}$ and 17 retrospective studies ${ }^{215157}$ 6870717578 80-83959899104 105); 27 studies reported adverse events (4 RCTs, ${ }^{353639106} 7$ prospective 42434558101107108 and 16 retrospective studies $20214851526869717579-819596109110$ ); 11 studies reported functional outcome (3 RCTs, ${ }^{35} 361114$ prospective $^{4245103112}$ and 4 retrospective studies 6273105113 ); 5 studies reported discharge location (2 prospective ${ }^{43} 114$ and 3 retrospective studies ${ }^{21} 4899$ ).

Thirteen potentially relevant ongoing trials were identified, with three (ISRCTN15165914, NCT03318133 and NCT02213380) planning to measure delirium postoperatively (online supplementary appendix B). No interim data were available.

\section{Study, population and intervention characteristics}

Given the large number of studies identified, only the 22 studies reporting the primary outcome of postoperative delirium have been described in detail (table 1).

\section{Primary outcome}

\section{Postoperative delirium}

Fifteen studies (four RCTs, ${ }^{36-39}$ six prospective studies ${ }^{1841-45}$ and five retrospective studies ${ }^{22} 48515254$ ) reporting unadjusted results are represented in the forest plot (figure 2). Of these 15 studies, only one study found a statistically significant benefit in favour of general anaesthesia ${ }^{52}$ and overall there was no evidence of a benefit of one type of anaesthesia over another. Seven studies were not included in forest plot due to insufficient data with five studies $^{4046475053}$ reported only as abstract, one RCT ${ }^{35}$ did not report delirium as dichotomous outcome and one retrospective study ${ }^{55}$ only included patients who developed delirium post surgery. Only two studies compared delirium according to anaesthetic types. One retrospective study that only included patients with delirium found GA to be a significant risk factor for immediate delirium (within 24 hours of surgery) compared with RA, but GA was not associated with delayed delirium (after 24 hours post surgery) ${ }^{55}$ A further study reported as abstract also found that delirium was more common with GA, but this did not remain statistically significant on multivariable analysis. The assessment tool for delirium was not stated. ${ }^{47}$

Overall, there was substantial heterogeneity across the 22 studies regarding assessment tools, assessment time-points and anaesthetic protocol. Many assessment tools were poorly defined. Only 7 out of 22 studies used either DSM-IV criteria ${ }^{1840495354}$ or Abbreviated Mental Test. ${ }^{350}$ Delirium or cognitive impairment was frequently not a primary outcome, but listed as one of several complications.

None of the RCTs that were quality assessed reported all relevant details (table 2A). Details were lacking on the delirium assessment tools used ${ }^{38}$ and method of randomisation. ${ }^{35363839}$ Blinding of outcome assessment was either not undertaken ${ }^{38}$ or unclear. ${ }^{36}$ There appeared to be no loss to follow-up in three RCTs, ${ }^{36} 3839$ but this was unclear for the other RCT. ${ }^{35}$ The RCT by Kamitani et al was not quality assessed as a full translation was not available. ${ }^{37}$

The observational studies were generally considered to be at low risk of bias in terms of patient eligibility; however, most had no details on blinding of outcome assessors and the level of completeness of data (table 2B). There was variation in reporting and adjustment of potential confounding factors such as the American Society of Anesthesiologists Physical Status Classification System (ASA) score, age, gender, comorbidities, surgery type, time to surgery and physical function. There were no details on characteristics of patients who completed follow-up compared with those lost to follow-up. There was also a general lack of detail on the type of assessment tool used and/or where the cut-off for a 'positive' diagnosis of delirium was.

\section{Secondary outcomes \\ Mortality}

Two RCTs reported mortality (table 3 ). One found a small and statistically significant survival benefit at 120 days and 1 year for GA, but no such benefit was evident at 30 or 90 days of follow-up. ${ }^{38}$ Ten observational studies reported adjusted results or results based on a matched analysis (table 3). Two of these ${ }^{2068}$ found a statistically significant benefit in favour of RA for in-hospital mortality. The remaining eight studies found no significant differences. There was a lack of consistency across studies in terms of number and type of variables included in models.

Of the remaining 46 studies (results not shown) reporting unadjusted mortality results only, six ${ }^{566067737476}$ found statistically significant results in favour of RA. The remainder found no statistically significant differences or benefit comparing RA with GA.

Overall, there is a paucity of good-quality evidence evaluating mortality, with only one good-quality $\mathrm{RCT}^{38}$ suggesting benefit from GA at later but not earlier time-points.

\section{Length of hospital stay}

Twenty-five 21363842455157586870717578 80-83 959899 101-105 studies reported length of hospital stay; nine could be included in a forest plot (figure 3). There was no difference in length of hospital stay based on one RCT. ${ }^{38}$ Three retrospective studies ${ }^{216881}$ compared patients with propensity score matching and showed a slight benefit towards a shorter length of stay with RA; while this was statistically significant in two studies, ${ }^{2168}$ the absolute reduction was small (up to around a third of a day). Results from the studies reporting unadjusted results were inconsistent, with three finding no difference $\mathrm{e}^{71750}$ and two finding a benefit from RA. ${ }^{82} 101$

Data were not available from the remaining 16 studies due to lack of data (three studies ${ }^{57} 7098$ were abstracts only, six studies 36427899104105 did not provide raw data, two studies ${ }^{4595}$ did not link data with types of anaesthesia and five studies 515883102103 only provided median length of stay). The $\mathrm{RCT}^{36}$ and the five prospective studies ${ }^{4245} 58102103$ 


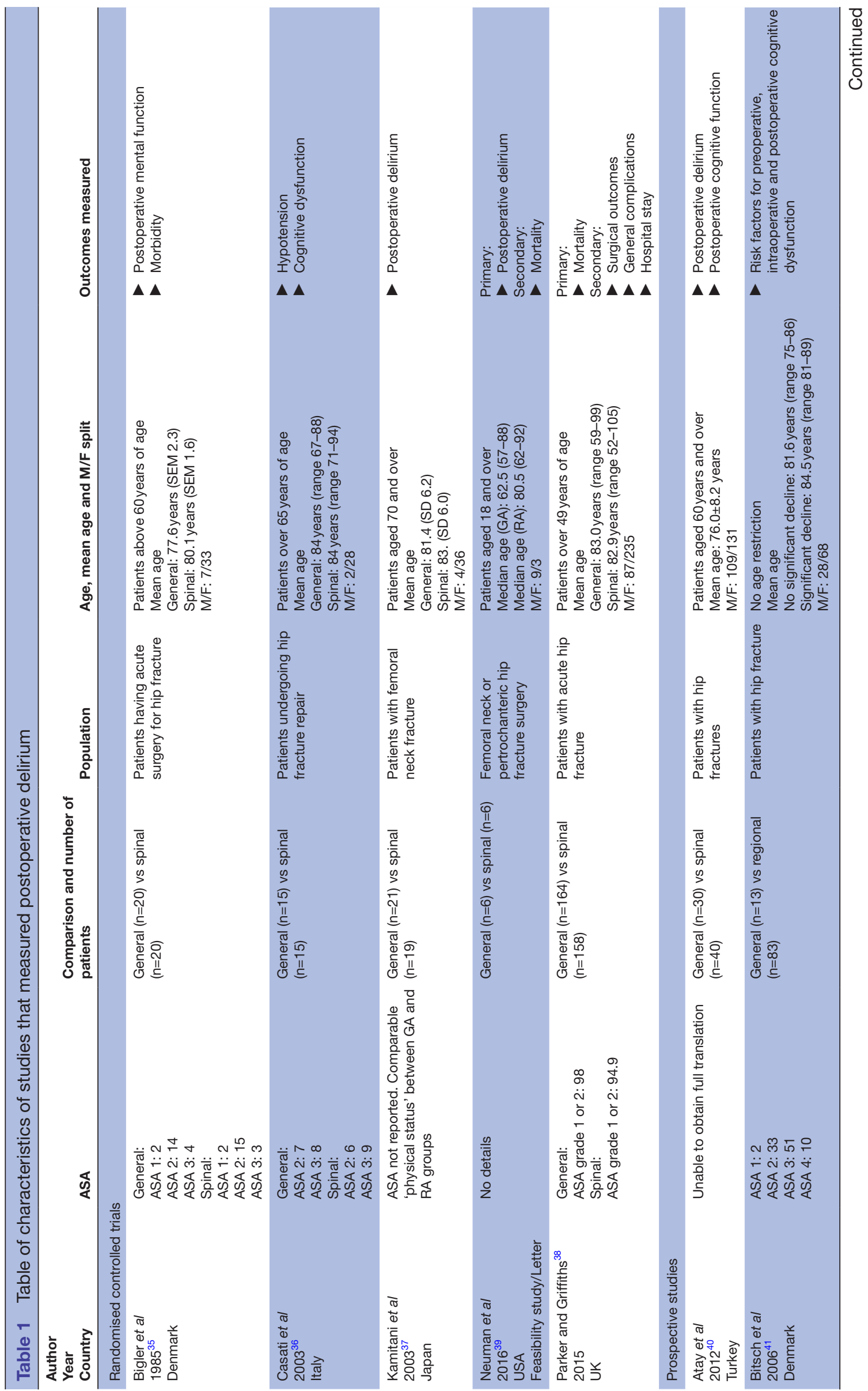




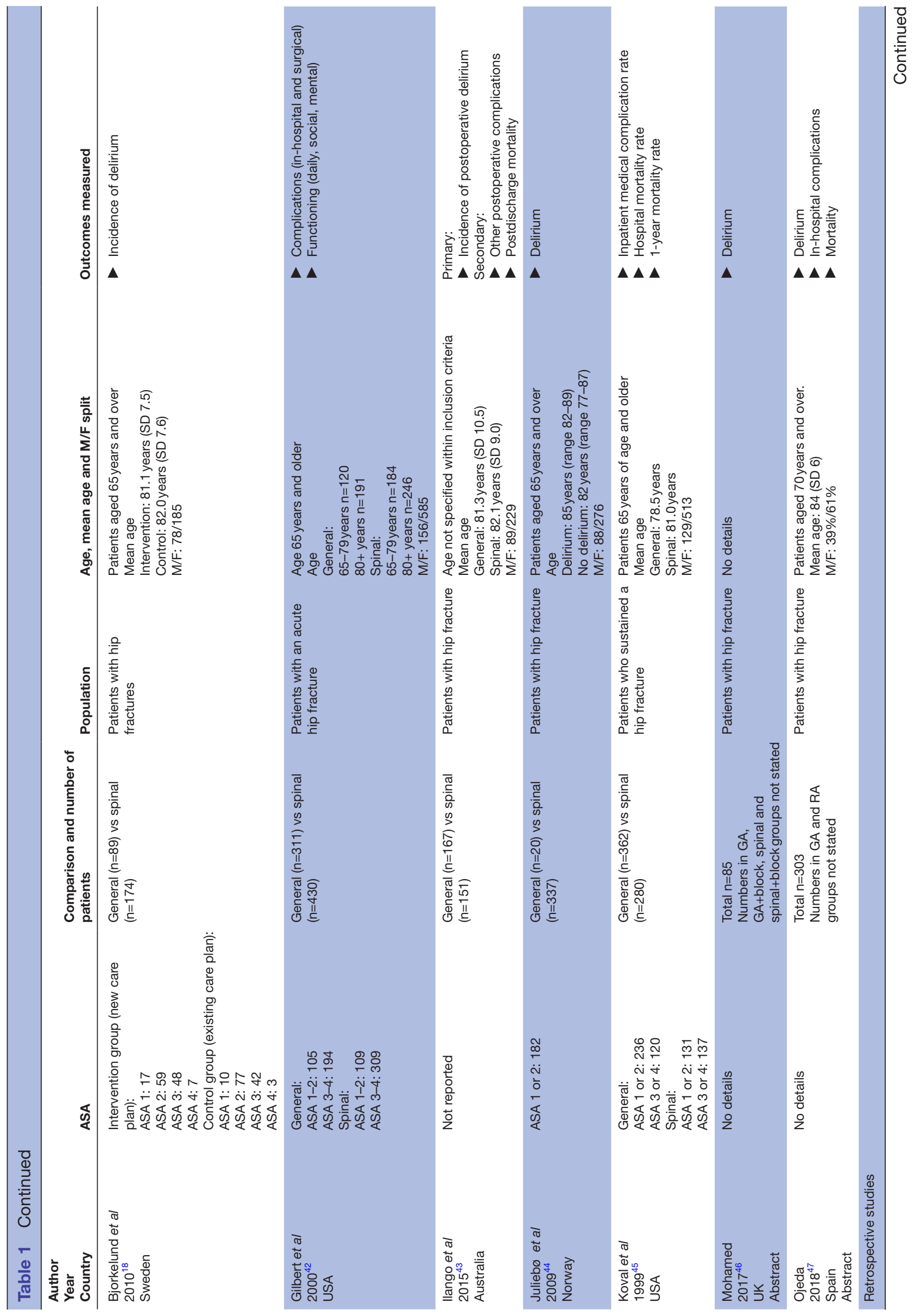




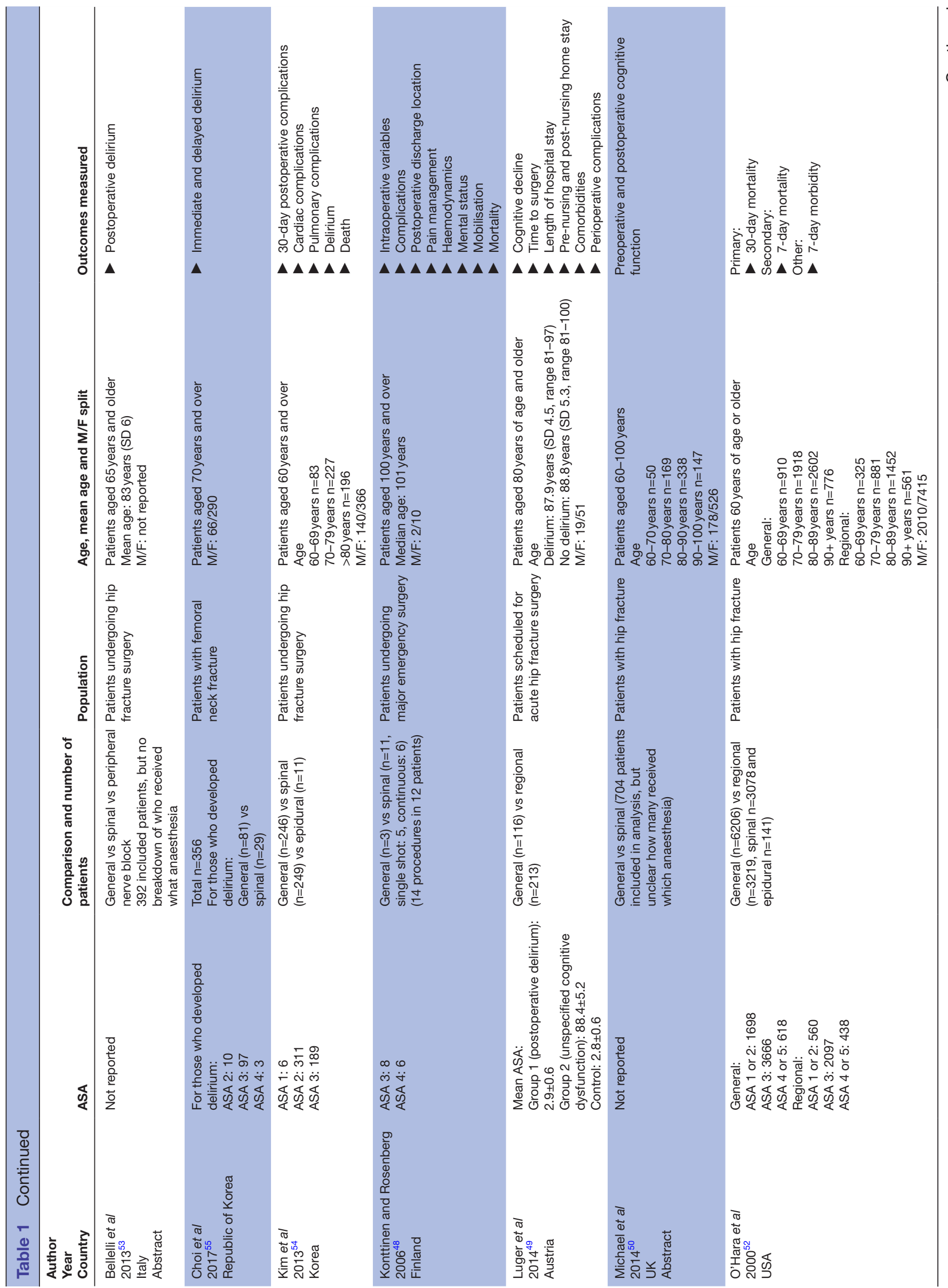




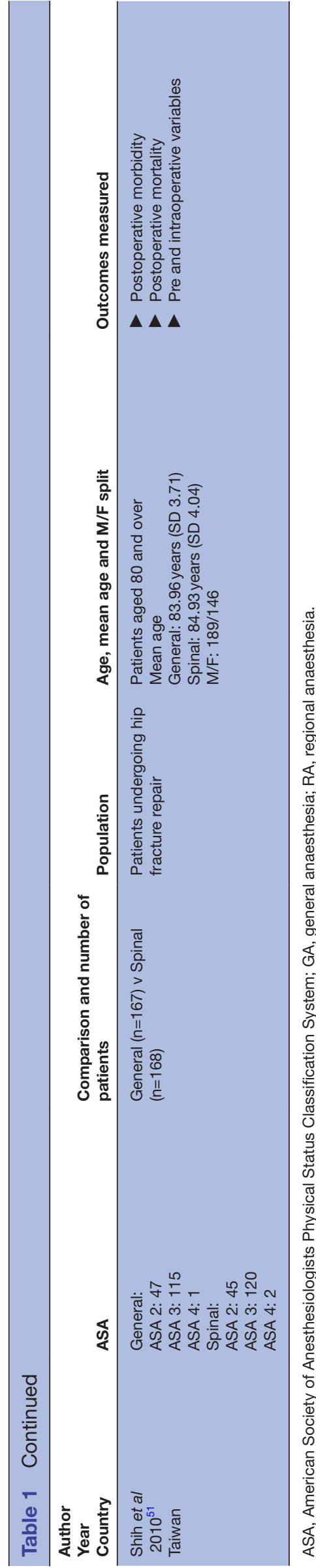

did not show any significant differences. Results from the 10 retrospective studies were also inconsistent: three studies $^{577083}$ reported no difference, four studies ${ }^{517899} 104$ found a statistically significant benefit for and one study ${ }^{95}$ reported a statistically significant benefit for GA. Fukuda et al reported a statistically significant effect in favour of spinal anaesthesia, but this effect was lost after propensity score matching. ${ }^{105}$ One large study (Nishi, $\mathrm{n}=16687$ ) reported in abstract form only reported a slightly shorter length of stay with RA; it was unclear if this was statistically significant. ${ }^{98}$

Most studies reported mean length of stay, but some also reported the median, which may be more appropriate. Of 12 studies $^{21} 364551577071839599102103$ reporting the median, nine studies ${ }^{21} 364557707183102103$ found no statistically significant differences. Three studies found a statistically significant difference in medians, two of which favoured $\mathrm{RA}^{51} 99$ and one favoured GA. ${ }^{95}$

\section{Adverse events}

Twenty-seven studies reported adverse events (table 4). There were many gaps in reporting of POMS adverse events, and it is uncertain whether this reflects non-occurrence or non-reporting of such events. Most commonly reported adverse events were pulmonary (10 studies) 20213545484962698991 and cardiovascular events (9 studies). ${ }^{21} 3539485868698195$ For pulmonary events, six studies found no statistically significant differences. ${ }^{354549698991}$ Four studies found a statistically significant difference in favour of RA (fewer cases of ventilatory support, ${ }^{68}$ respiratory failure ${ }^{2068}$ and 'overall pulmonary' adverse events ${ }^{20}{ }^{51}$ ). There were no differences in occurrences of pneumonia ${ }^{35} 485295$ or hypoxia. ${ }^{75101}$ The most commonly reported cardiovascular adverse events were myocardial infarction ${ }^{39486895}$ and thromboembolic events. ${ }^{35} 58698195$ No differences were found for myocardial infarction. ${ }^{39} 4852687595$ Three studies ${ }^{698195}$ reported higher incidence of thromboembolic events in GA group.

Nine studies summarised overall adverse events with the majority finding no differences between the types of anaesthesia. Where there was a significant difference, this was in favour in RA (eg, fewer incidences of 'all complications, ${ }^{5169}$ intensive treatment unit (ITU) admissions, ${ }^{68}$ stroke $^{68}$ or requirement for blood transfusion). Three studies $^{106} 108109$ found higher incidences of hypotension in the GA group.

The results are thus suggestive of a lower incidence of postoperative respiratory, cardiac and overall complications in the RA group. However, reporting of adverse events, including methods of ascertainment, was inconsistent and limited.

\section{Functional outcomes}

Eleven studies reported functional outcomes using a variety of outcome measures. Two RCTs reported a significantly quicker time to ambulation in the RA group (3.3 days RA vs 5.5 days GA) ${ }^{35}$ and a statistically significant earlier discharge time from PACU (post-anaesthesia care 


\begin{tabular}{|c|c|c|c|}
\hline Study & Assessment tool & Time-point & $\operatorname{RR}(95 \% \mathrm{Cl})$ \\
\hline \multicolumn{4}{|l|}{$\mathrm{RCT}$} \\
\hline Casati 2003 & MMSE $\geq 2$ point decline & Day 1 post-op & $1.13(0.60,2.11)$ \\
\hline Casati 2003 & MMSE $\geq 2$ point decline & Day 7 post-op & $3.00(0.35,25.68)$ \\
\hline Kamitani 2003 & CAM & Day 0-1 & $0.68(0.29,1.60)$ \\
\hline Kamitani 2003 & CAM & Day $1-2$ & $1.13(0.35,3.60)$ \\
\hline Kamitani 2003 & CAM & Day 2-3 & $1.81(0.18,18.39)$ \\
\hline Kamitani 2003 & CAM & Day 3-4 & $2.73(0.12,63.19)$ \\
\hline Neuman 2016 & CAM & Day 1-5 post-op & $-5.00(0.29,86.43)$ \\
\hline Parker \& Griffiths 2015 & Unclear & Unclear & $0.14(0.01,2.64)$ \\
\hline \multicolumn{4}{|l|}{ Prospective } \\
\hline$\overline{\text { Bitsch } 2006}$ & MMSE $\geq 4$ point decline & Day 2-7 & $1.23(0.58,2.62)$ \\
\hline Bitsch 2006 & MMSE $\geq 50 \%$ & Day 2-7 & $0.85(0.22,3.30)$ \\
\hline Björkelund 2010 (SC) & OBS + DSM-IV & After 8 hours minimum post-op & $1.57(0.98,2.50)$ \\
\hline Björkelund 2010 (MFIP) & OBS + DSM-IV & After 8 hours minimum post-op & $0.75(0.35,1.61)$ \\
\hline Gilbert 2000 & Unclear & Typically 5-10 days post-op & $1.01(0.82,1.25)$ \\
\hline Ilango 2015 & Clinical judgement + beh obs & Any time during post-operative recovery & $0.86(0.70,1.06)$ \\
\hline Juliebo 2009 & CAM & Up to 5 days post-op & $0.49(0.14,1.73)$ \\
\hline Koval 1999 & Unclear & Not specified & $0.35(0.12,1.00)$ \\
\hline \multicolumn{4}{|l|}{ Retrospective } \\
\hline Kim 2013 & DSM-IV & Within 30 days & $1.17(0.72,1.89)$ \\
\hline Kontinnen 2006 & Unclear & Within 5 days post-op & $0.88(0.19,4.03)$ \\
\hline Luger 2014i & DSM-IV & Not specified & $1.47(0.60,3.62)$ \\
\hline Luger 2014ii & DSM-IV or UCD & Not specified & $1.30(0.85,1.97)$ \\
\hline O'Hara 2000 & Unclear & Within 7 days & $0.73(0.68,0.78)$ \\
\hline \multirow[t]{2}{*}{ Shih 2010} & Unclear & Before discharge & $6.04(0.73,49.59)$ \\
\hline & & 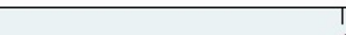 & \\
\hline
\end{tabular}

Figure 2 Forest plot of studies reporting the unadjusted relative risk of postoperative delirium with GA compared with spinal anaesthesia. Some studies are represented more than once to show results for different definitions of delirium or for different assessment time-points. CAM, confusion assessment method; DSM-IV, Diagnostic and Statistical Manual of Mental Disorders, 4th edition; MFIP, Multi-factorial Intervention Program; MMSE, Mini-Mental State Examination; RR, relative risk; SC, standard care; UCD, unspecified cognitive dysfunction.

unit) in the RA group (RA 15 (5-30) min vs GA 55 (15-80) min, $\mathrm{p}=0.0005) .{ }^{36}$ However, one RCT found that patients given RA were slower to be discharged from PACU (mean time to discharge GA 35.04 min (SD 3.39) vs RA $41.26 \mathrm{~min}$ (SD 8.37), $\mathrm{p}=0.001) .{ }^{111}$ No significant differences were found in the non-randomised studies regarding time to ambulation, ${ }^{103112113}$ walking speed, ${ }^{62}$ time to rise from chair, ${ }^{42}$ mean Barthel's score ${ }^{73}$ or ambulation at 3, 6 and 12 months post surgery. ${ }^{45} 105$ Overall results may suggest a small benefit from RA for immediate post-anaesthetic mobilisation. However, the evidence is limited by small sample size, unknown method of outcome assessment and blinding of assessors.

\section{Discharge location}

Five non-randomised studies described discharge locations of patients following hip fracture. ${ }^{21} 434899114$ One study with only 14 patients reported that more patients returned home in the RA group. ${ }^{45}$ A large retrospective study reported lower odds of returning to home residence and higher chance of admitting to healthcare facility in GA group compared with RA (16695 patients, return home adjusted OR 0.91 (95\% CI 0.84 to 0.97$)$; healthcare facility admission OR 1.10 (95\% CI 1.03 to 1.19). ${ }^{99}$ A cohort study of 4815 patients found operation under GA significantly increased risks of rehabilitation admission instead of home (adjusted OR 1.74, 95\% CI 1.34 to $2.25, \mathrm{p}<0.001) .{ }^{114}$ However, two larger studies ${ }^{21} 109$ found no difference in discharge location between GA or RA groups.

\section{Quality of life}

There were no studies that evaluated the effect of type of anaesthesia on quality of life in patients after hip fracture surgery.

\section{DISCUSSION}

For the primary outcome of postoperative delirium, this systematic review did not find any difference between types of anaesthesia. Furthermore, no survival benefit could be demonstrated with either type of anaesthesia up to 1 year postoperatively. A small number of studies suggested that fewer adverse events might be associated with RA. Similarly, some studies were suggestive of a small reduction in hospital stay with RA. Data were limited for functional outcomes and discharge data. Two small RCTs suggested a benefit from RA for immediate post-anaesthetic mobilisation. There were no studies that reported on quality of life after different types of anaesthesia.

This is the most comprehensive and methodologically robust systematic review to date. It includes both RCTs 







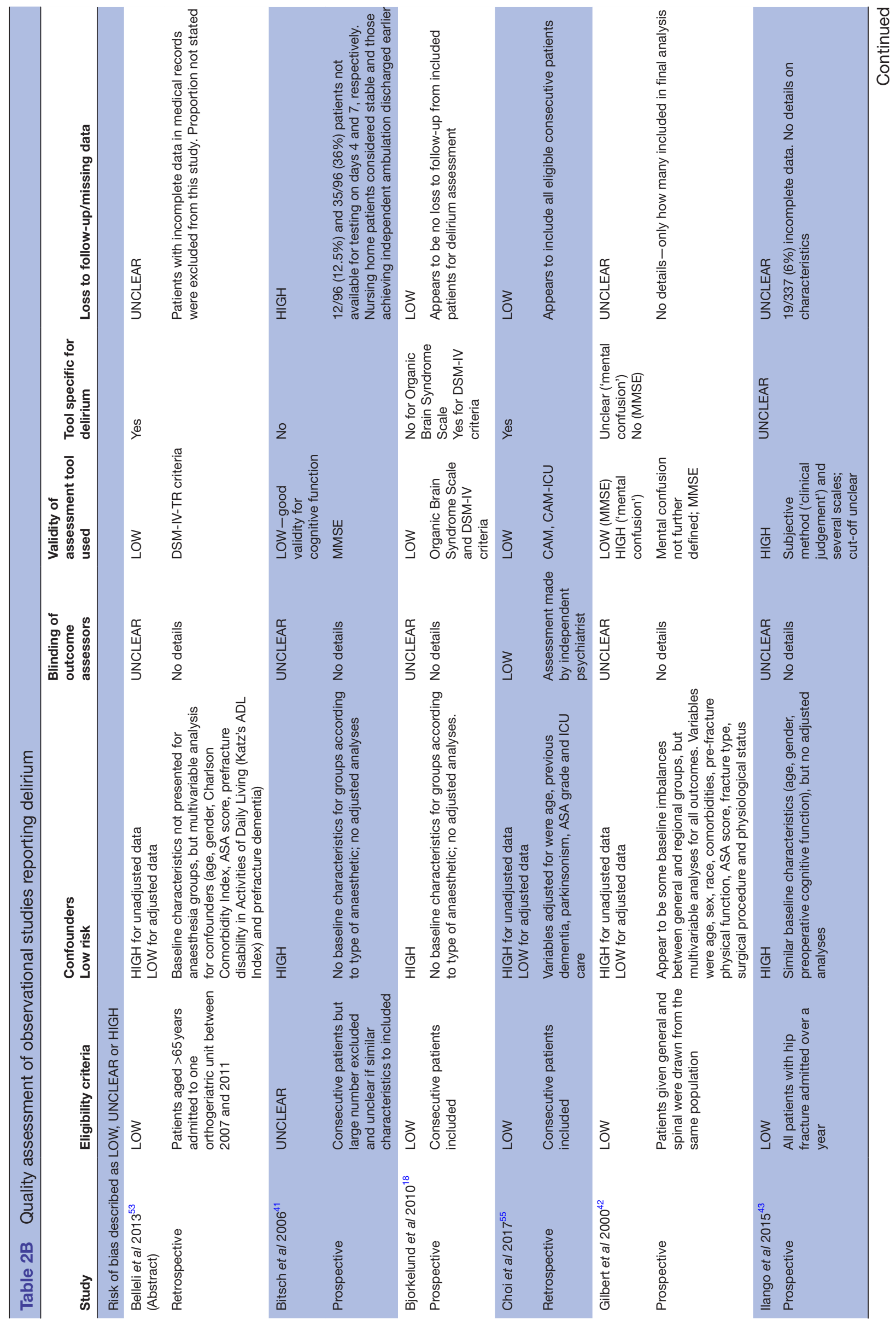




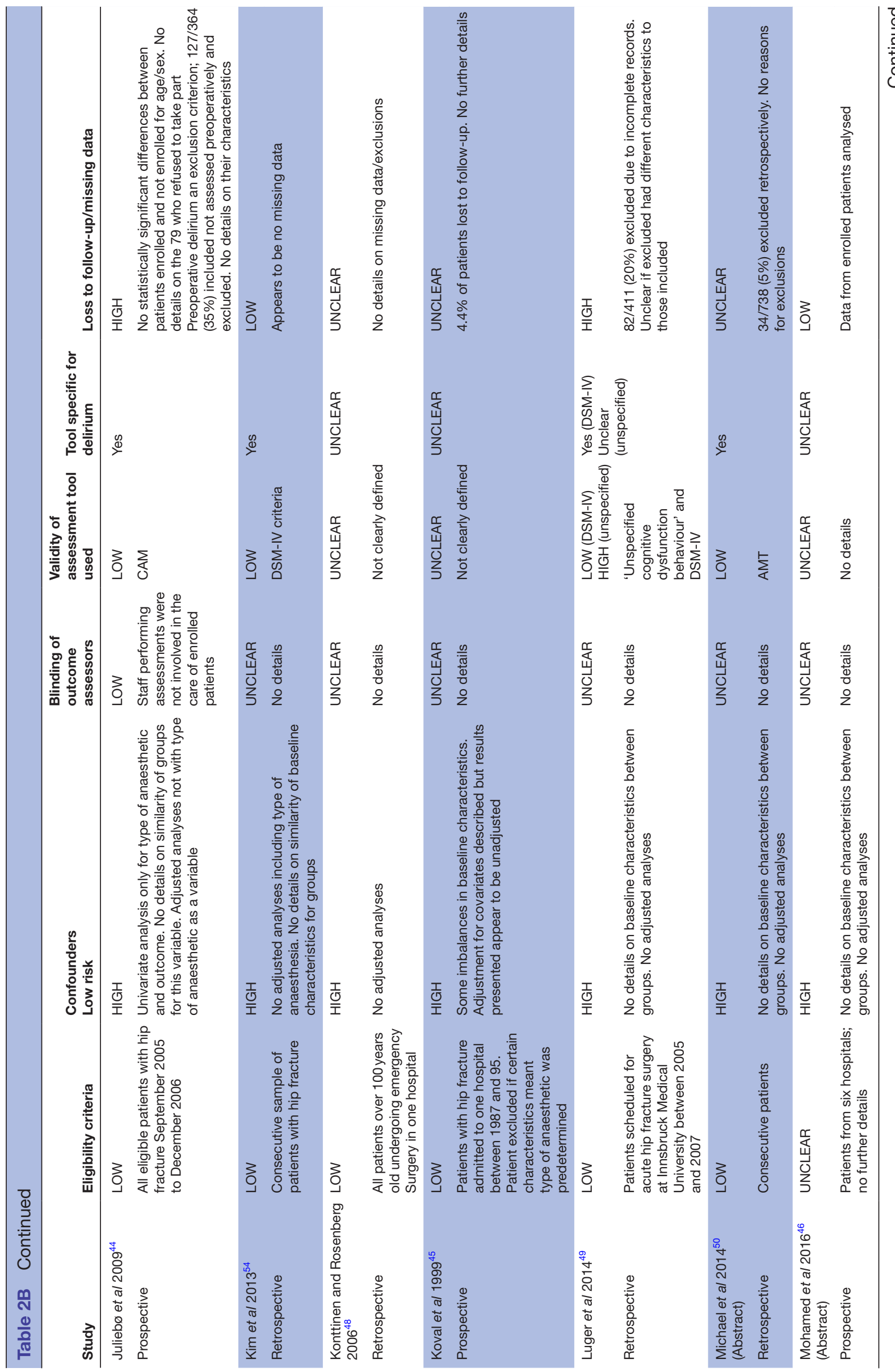




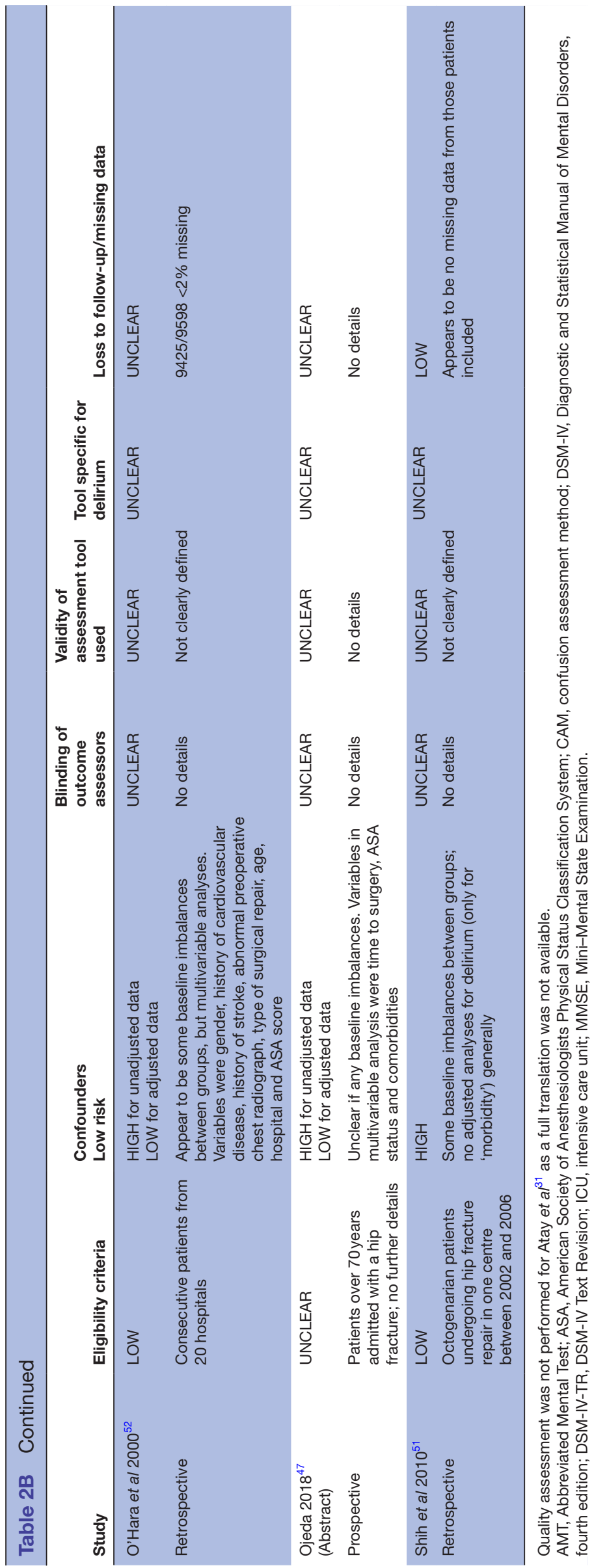




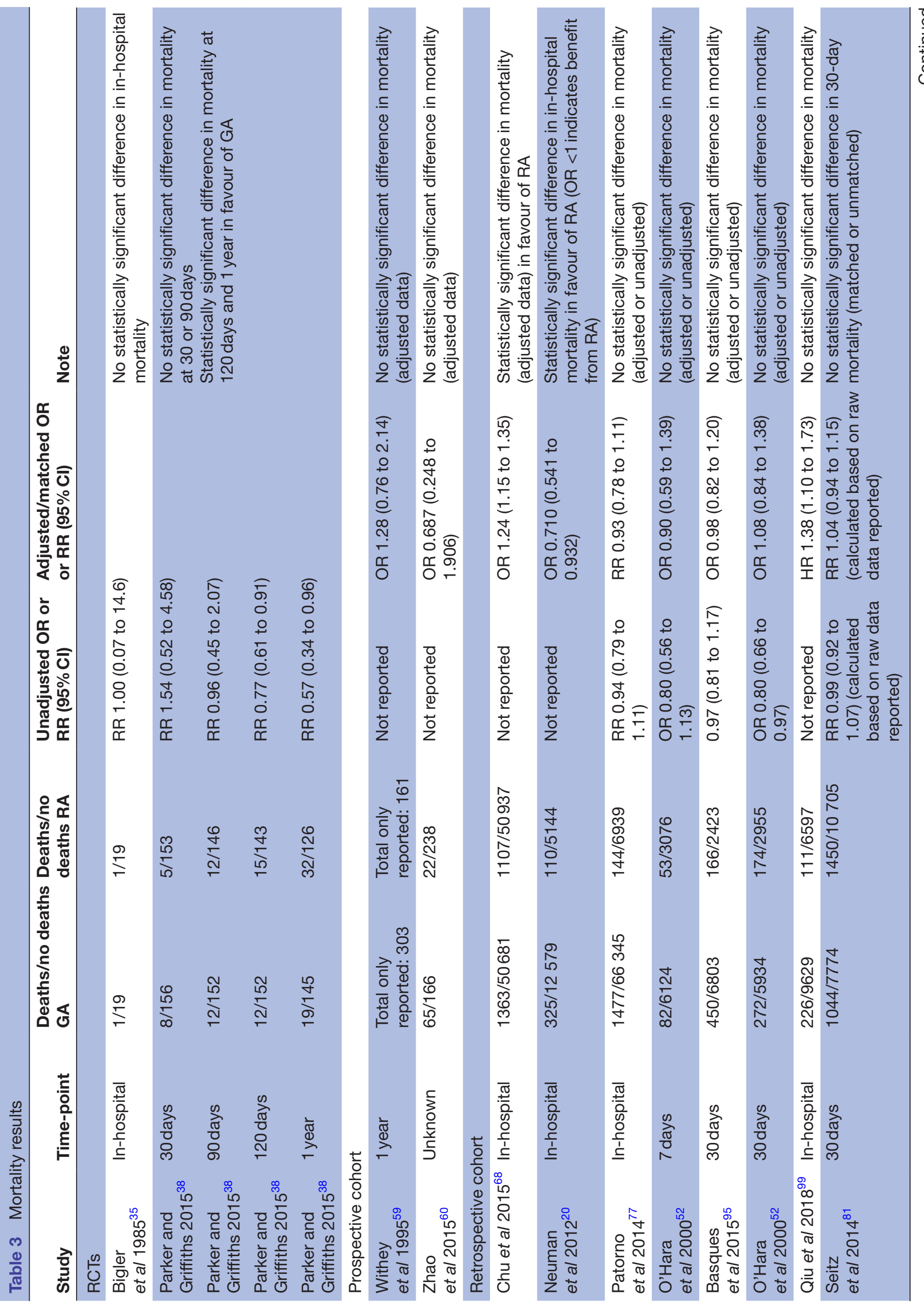


and non-randomised controlled studies, focusing on delirium as a primary outcome as well as synthesising findings for a range of other important outcomes including adverse events. Results for RCTs, non-randomised studies, adjusted and unadjusted results were presented and considered separately. It was anticipated that non-randomised studies, which are more prone to bias, may overestimate effect sizes compared with RCTs. No such trends were observed, however, as studies of any design mostly showed no difference in effect.

A sensitive search strategy means it is unlikely that many studies would have been missed. Careful consideration of heterogeneity has meant that no meta-analyses were undertaken, but results were presented in forest plots where possible to show the overall direction of effect and heterogeneity between studies.

Delirium can be diagnosed using the criteria from the DSM-V or WHO's ICD-10 classification of diseases. ${ }^{7115}$ However, in clinical practice, the criteria can be difficult to apply ${ }^{116}$ and tools such as the confusion assessment method, Delirium Rating Scale revised-98, Neelon and Champagne Confusion Scale ${ }^{117}$ or 4 'A's' Test have been advocated as validated screening tools. ${ }^{6116} 118$ No consensus exists in the literature as to which tool should be the gold standard. ${ }^{6119} 120$ The accurate assessment of delirium can be affected by the presence of pain and residual drugs in the immediate period following surgery; therefore, timing of assessment is also important. ${ }^{121}$ No significant differences were found for the incidence of postoperative delirium, based on 4 RCTs and 14 non-randomised studies, but there were significant differences in the assessment tools and the assessment time-points. Most of the RCTs were small and most likely underpowered. In the largest RCT, ${ }^{38}$ delirium was not a primary outcome and the assessment tool used or the timing of assessments was not reported. The pathophysiology of delirium remains poorly understood, but there are a combination of pre-existing and precipitating factors that can predispose the patient to postoperative delirium. ${ }^{11} 122123$ Pre-existing patient risk factors including age $>70$ years, pre-existing cognitive impairment, history of postoperative delirium, visual impairment, cerebrovascular disease and renal impairment ${ }^{124} 125$ are associated with higher risk of delirium. Precipitating factors can include acute injury such as a hip fracture, malnutrition, electrolyte imbalance and the use of urinary catheter and physical restraints. ${ }^{125}$ Specific perioperative risk factors include intraoperative blood loss, postoperative transfusions and severe acute pain. ${ }^{126} 127$ The studies that adjusted for confounders and reported delirium ${ }^{40} 425253$ found no association between type of anaesthesia and postoperative delirium. Confounders adjusted for included demographics, ASA classification, comorbidities, nutritional status, fracture type, preoperative blood transfusion and readmission. ${ }^{42} 5253$ However, with multifactorial risk factors for delirium, it is difficult to encompass all variables. Other important characteristics such as anaemia, time to surgery, blood loss, intraoperative hypotension and sedation can also influence outcome but were less frequently included as variables. Given the lack of consistency across studies in 


\begin{tabular}{|c|c|c|c|c|c|}
\hline Study & $\begin{array}{l}\text { Study } \\
\text { design }\end{array}$ & $\begin{array}{l}\text { Anaesthesia } \\
\text { type }\end{array}$ & $\begin{array}{l}\text { No. } \\
\text { GA }\end{array}$ & $\begin{array}{l}\text { No. } \\
\text { RA }\end{array}$ & WMD $(95 \% \mathrm{Cl})$ \\
\hline \multicolumn{6}{|l|}{$\underline{\mathrm{RCT}}$} \\
\hline \multirow[t]{2}{*}{ Parker 2015} & RCT & Spinal & 164 & 158 & $-0.30(-3.39,2.79)$ \\
\hline & & & & & $-0.30(-3.39,2.79)$ \\
\hline \multicolumn{6}{|l|}{ Adiusted } \\
\hline Chu 2015 & Retrospective & Neuraxial & 52044 & 52044 & $0.33(0.24,0.42)$ \\
\hline Le-Wendling 2012 & Retrospective & Regional & 235 & 73 & $0.19(0.11,0.27)$ \\
\hline Seitz 2014 & Retrospective & Regional & 6135 & 6135 & $0.10(-0.68,0.88)$ \\
\hline \multicolumn{6}{|l|}{$\underline{\text { Unadiusted }}$} \\
\hline Naja 2000 & Prospective & Combined Sciatic/ PNB & 30 & 30 & $\longrightarrow \quad 6.90(4.57,9.23)$ \\
\hline Hekimoglu Sahin 2012 & Retrospective & Spinal \& Epidural & 67 & 118 & $-0.28(-2.79,2.23)$ \\
\hline Le Liu 2014 & Retrospective & Peripheral nerve blocks & 72 & 145 & $0.57(-0.70,1.84)$ \\
\hline Rashid 2013 & Retrospective & Regional & 107 & 87 & $0.72(-1.15,2.59)$ \\
\hline Sykora 1988 & Retrospective & Epidural & 201 & 142 & $\longrightarrow 8.20(5.21,11.19)$ \\
\hline
\end{tabular}

Figure 3 Forest plot of studies reporting length of hospital stay. Weighted mean difference in number of days between GA and RA (GA minus RA). WMD $>0$ means longer stay for GA and favours RA. WMD $<0$ means longer stay for RA and favours GA. GA, general anaesthesia; RA, regional anaesthesia; RCT, randomised controlled trial; WMD, weighted mean difference.

terms of number and type of variables included in models and the reporting of these, it is not possible to gauge the overall impact that adjusting for confounders may have on the direction of effect.

There were limitations in the primary data included in this systematic review. There were a limited number of RCTs (3\% of total number of patients included for the primary outcome) and many of the non-randomised studies did not make any attempts to adjust for potential confounding factors. When confounding variables were considered, this was often done for mortality only. There was significant heterogeneity across studies in study design, population age, comparators, assessment time-points and definition of outcomes (particularly delirium) that precluded quantitative pooling.

Detailed reporting of anaesthetic techniques was suboptimal especially for GA techniques. RA techniques employed were more commonly reported, but the specific drugs used were not described. Opioids are known to cause delirium ${ }^{3128}$ and acute pain is a well-recognised precipitating factor of delirium, but both were poorly reported. While most studies planned to collect adverse events data, it was unclear whether adverse events were predetermined. Small sample sizes $(n<30)$ and rare occurrences of adverse events mean that many studies were likely underpowered. ${ }^{35} 3648101$ The style of data reporting in included studies could also lead to over-reporting of complications; for example, a patient could develop pneumonia, which led to respiratory failure and the need for inotropic and ventilatory support and ITU admission. Thus, five adverse events would be attributable to a single patient, but this may not be evident from the data. Incidence of intraoperative hypotension was not captured by POM categories, as inotropic support use was not reported. Hypotension can lead to hypoperfusion and organ damage. A recent analysis of data from an audit of outcomes in patients with hip fracture demonstrated increased risk of death associated with intraoperative hypotension. In our review, three studies ${ }^{106} 108109$ examined hypotension, all of which found higher incidences of hypotension in the GA group. Four studies ${ }^{52} 69106109$ also found significantly higher volumes of fluids and blood products transfused in the GA group.

Subgroup analysis was not feasible and no individual studies reported findings for different subgroups. It is possible that there are some patients who may, in some circumstances, benefit from RA compared with GA that have not been captured by the evidence presented in this systematic review. Subgroup analysis of specific at-risk patients, for example the frail and the very elderly, may suggest a benefit for either regional or general anaesthesia in certain population groups.

Older patients are at high risk of adverse outcomes postoperatively due to age-related physiological decline, multiple comorbidities and polypharmacy. ${ }^{129}$ Principles of care for older patients in the perioperative setting should employ an anaesthetic technique that leads to rapid recovery, dosing of drugs specific to individual pharmacokinetic variation and appropriate pain management strategies. ${ }^{130}$ Most recently, 
Table 4 Summary findings table of studies reporting adverse events

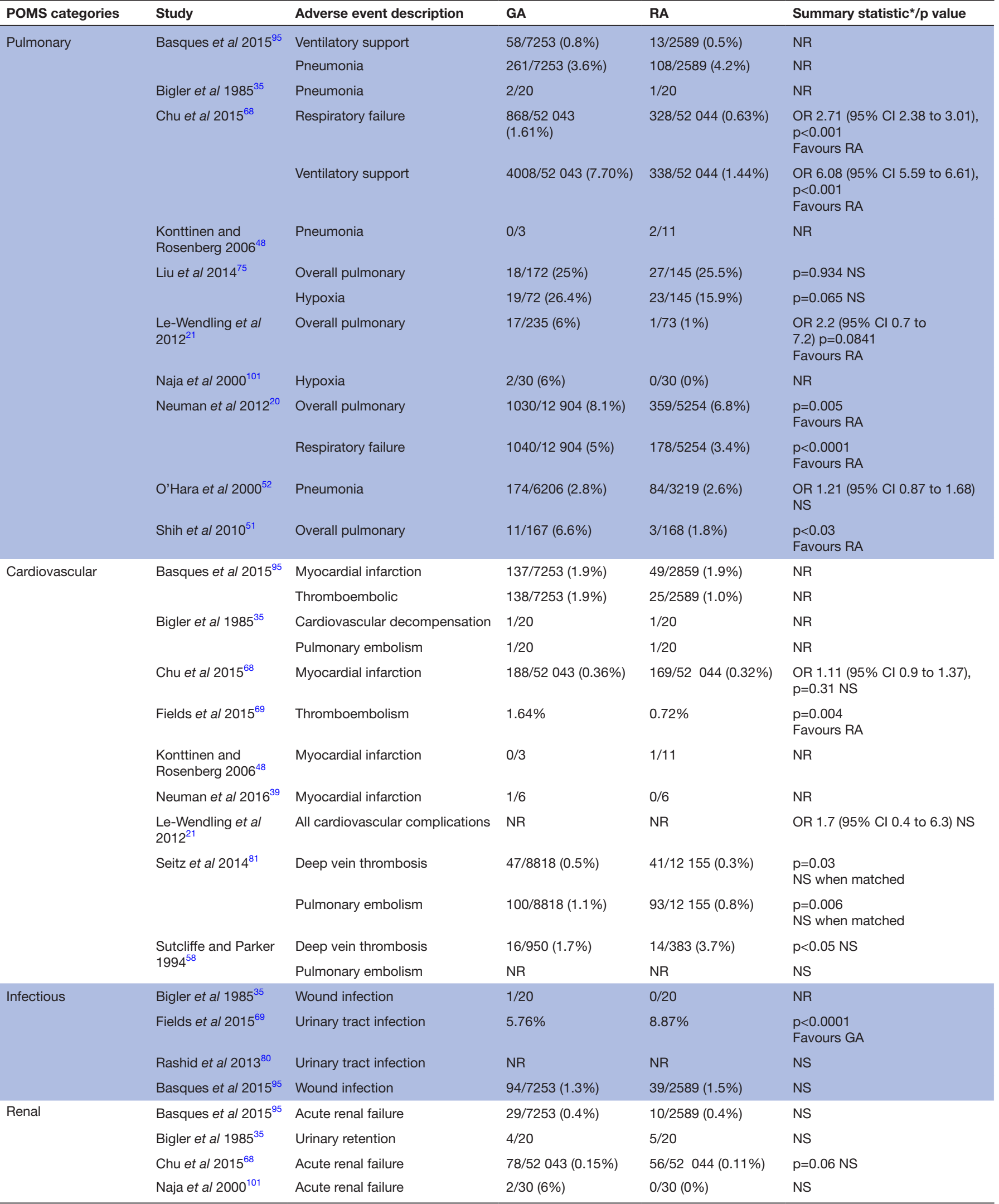

Continued 
Table 4 Continued

\begin{tabular}{|c|c|c|c|c|c|}
\hline POMS categories & Study & Adverse event description & GA & RA & Summary statistic ${ }^{\star} / p$ value \\
\hline \multirow[t]{15}{*}{ Overall complications } & Gilbert et al $2000^{42}$ & Serious medical complications & $55 / 311(17.7 \%)$ & $79 / 430(18.4 \%)$ & OR $0.92(95 \% \mathrm{Cl} 0.61$ to 1.4$) \mathrm{NS}$ \\
\hline & \multirow[t]{3}{*}{$\begin{array}{l}\text { Gilbert et al } 2000^{42} \\
\text { Whiting et al } 2015^{96}\end{array}$} & Fewer medical complications & $109 / 311(35.1 \%)$ & $151 / 430(35.1 \%)$ & $\begin{array}{l}\text { OR } 1.28(95 \% \mathrm{Cl} 0.90 \text { to } 1.82) \\
\text { NS }\end{array}$ \\
\hline & & Surgical complications & $15 / 311(4.8 \%)$ & $19 / 430(4.4 \%)$ & $\begin{array}{l}\text { OR } 1.08(95 \% \mathrm{Cl} 0.65 \text { to } 1.21) \\
\text { NS }\end{array}$ \\
\hline & & Major complications & NR & NR & $\begin{array}{l}\text { OR } 1.43(95 \% \mathrm{Cl} 1.16 \text { to } 1.77) \\
\text { NS }\end{array}$ \\
\hline & \multirow[t]{3}{*}{$\begin{array}{l}\text { Whiting et al } 2015^{96} \\
\text { Fields et al } 2015^{69}\end{array}$} & Minor complications & NR & NR & $\begin{array}{l}\text { OR } 1.02(95 \% \mathrm{Cl} 0.82 \text { to } 1.26) \\
\text { NS }\end{array}$ \\
\hline & & All complications & NR & NR & $\begin{array}{l}\text { OR } 1.24(95 \% \mathrm{Cl} 1.05 \text { to } 1.48) \\
\text { NS }\end{array}$ \\
\hline & & All complications & $2357 / 4813(48.97 \%)$ & $830 / 1815(45.75 \%)$ & $\begin{array}{l}\text { OR } 1.29(95 \% \mathrm{Cl} 1.13 \text { to } 1.47) \\
\mathrm{p}=0.0002 \\
\text { Favours RA }\end{array}$ \\
\hline & $\begin{array}{l}\text { Hekimoglu } \\
\text { Sahin et al } 2012^{71}\end{array}$ & All complications & NR & NR & NS \\
\hline & llango et al $2015^{43}$ & All complications & NR & NR & NS \\
\hline & Koval et al $1999^{45}$ & All complications & $41 / 362(11.3 \%)$ & $32 / 280(11.4 \%)$ & NS \\
\hline & Liu et al $2014^{75}$ & All complications & $17 / 72(23.6 \%)$ & $50 / 145(34.5 \%)$ & $p=0.165 \mathrm{NS}$ \\
\hline & $\begin{array}{l}\text { Le-Wendling et al } \\
2012^{21}\end{array}$ & All complications & NR & NR & OR $1.7(95 \% \mathrm{Cl} 0.7$ to 4.1$) \mathrm{NS}$ \\
\hline & Rashid et al $2013^{80}$ & All complications & $22 \%$ & $19 \%$ & $\begin{array}{l}\text { Log regression model } p=0.002 \\
\text { Favours } R A\end{array}$ \\
\hline & Shih et al $2010^{51}$ & All complications & $21 / 167(12.6 \%)$ & $9 / 168(5.4 \%)$ & $\begin{array}{l}\mathrm{p}<0.02 \\
\text { Favours RA }\end{array}$ \\
\hline & Chu et al $2015^{68}$ & ITU admissions & $5743 / 52043(11.03 \%)$ & $3205 / 52044(6.16 \%)$ & $\begin{array}{l}\text { OR } 1.95 \text { ( } 95 \% \mathrm{Cl} 1.87 \text { to } 2.05) \\
\mathrm{p}<0.001 \\
\text { Favours RA }\end{array}$ \\
\hline \multirow[t]{13}{*}{ Specific complications } & Chu et al $2015^{68}$ & ITU stay $>3$ days & $1206 / 52043(2.32 \%)$ & $411 / 52044$ (0.79\%) & $\begin{array}{l}\mathrm{p}<0.001 \\
\text { Favours RA }\end{array}$ \\
\hline & $\begin{array}{l}\text { Baumgarten et al } \\
2012^{107}\end{array}$ & Pressure ulcers & $10 / 328(3.0 \%)$ & $18 / 313(5.8 \%)$ & $\begin{array}{l}\text { OR } 1.3(95 \% \mathrm{Cl} 1.0 \text { to } 1.6) \\
\text { Favours GA }\end{array}$ \\
\hline & Casati et al $2003^{36}$ & $\begin{array}{l}\text { Hypotension requiring crystalloid } \\
\text { infusion }\end{array}$ & $12 / 15(80 \%)$ & $7 / 15(46 \%)$ & $p=0.05 \mathrm{NS}$ \\
\hline & Maia et al $2014^{108}$ & Intraoperative hypotension & $25 / 50$ & $80 / 173$ & $\begin{array}{l}\mathrm{p}=0.014 \\
\text { Favours RA }\end{array}$ \\
\hline & Minville et al $2008^{109}$ & Intraoperative hypotension & $35 / 42(83 \%)$ & $74 / 109$ (68\%) & NS \\
\hline & Gadsden $2016^{110}$ & Intraoperative hypotension & $569 / 745$ & $1144 / 1528$ & $\begin{array}{l}\text { Favours RA } \\
\mathrm{p}<0.0001\end{array}$ \\
\hline & Messina et al $2013^{106}$ & $\begin{array}{l}\text { Haemodynamic changes first } \\
10 \mathrm{~min}\end{array}$ & \multicolumn{2}{|c|}{$\begin{array}{l}\text { Mean arterial blood pressure, heart rate, } \\
\text { systemic vascular resistance index changes. } \\
\text { More disturbance in GA }\end{array}$} & Favours RA \\
\hline & Basques et al $2015^{95}$ & Blood transfusion & $2843 / 7253$ (39.2\%) & $851 / 2589(32.9 \%)$ & $\begin{array}{l}\text { Matched OR } 1.34(95 \% \mathrm{Cl} 1.22 \\
\text { to } 1.49), \mathrm{p}<0.001 \\
\text { Favours RA }\end{array}$ \\
\hline & Fields et al $2015^{69}$ & Blood transfusion & $45.49 \%$ & $39.34 \%$ & $\begin{array}{l}\mathrm{p}<0.0001 \\
\text { Favours RA }\end{array}$ \\
\hline & Minville et al $2008^{109}$ & Blood transfusion & $23 \%$ & $4 \%$ & $\begin{array}{l}\mathrm{p}<0.05 \\
\text { Favours RA }\end{array}$ \\
\hline & Shih et al $2010^{51}$ & Blood loss & $\begin{array}{l}\text { Median } 250(0- \\
\text { 1600) } \mathrm{mL}\end{array}$ & $\begin{array}{l}\text { Median } 200(0- \\
\text { 1200) } \mathrm{mL}\end{array}$ & $\begin{array}{l}\mathrm{p}=0.01 \\
\text { Favours RA }\end{array}$ \\
\hline & Chu et al $2015^{68}$ & Stroke & $840 / 52043(1.61 \%)$ & $717 / 52044$ (1.38\%) & $\begin{array}{l}\text { OR } 1.18(95 \% \mathrm{Cl} 1.07 \text { to } 1.31) \\
\mathrm{p}=0.001 \\
\text { Favours RA }\end{array}$ \\
\hline & Liu et al $2014^{75}$ & Stroke & $5 / 72(5.9 \%)$ & $4 / 145$ (2.8\%) & $\mathrm{p}=0.145 \mathrm{NS}$ \\
\hline
\end{tabular}

${ }^{*} \mathrm{OR}, \mathrm{GA}$ vs RA.

GA, general anaesthesia; ITU, intensive treatment unit; NR, not reported; NS, not significant; POMS, postoperative morbidity survey; RA, regional anaesthesia. 
the European Society of Anaesthesiology consensus guideline on postoperative delirium also did not find substantial evidence to recommend a specific type of anaesthetic technique but advocates intraoperative monitoring to avoid swings in blood pressure and excessive depth of anaesthesia. ${ }^{131}$ Given the lack of standardised assessment tools of delirium and the paucity of suitably powered, methodologically sound studies, uncertainty remains regarding any potential benefits of certain types of anaesthesia. However, even a modest reduction in adverse events and length of hospital stay could benefit many patients and result in cost savings for healthcare providers. Future research examining postoperative delirium should include robust assessment and diagnosis of delirium. There is also an urgent need for high-quality research comparing anaesthetic techniques that focus on patient-related outcomes such as quality of life and functional outcomes.

\section{Author affiliations}

${ }^{1}$ Institute of Inflammation and Ageing, College of Medical and Dental Sciences, University of Birmingham, Birmingham, UK

${ }^{2}$ Birmingham Clinical Trials Unit, University of Birmingham, Birmingham, UK ${ }^{3}$ Biostatistics, Evidence Synthesis and Test Evaluation (BESaTE), Institute of Applied Health Research, College of Medical and Dental Sciences, University of Birmingham, Birmingham, UK

${ }^{4}$ Warwick Medical School, University of Warwick, Coventry, UK

${ }^{5}$ Department of Anaesthesia and Critical Care, Birmingham Heartlands Hospital, University Hospital Birmingham NHS Foundation Trust, Birmingham, United Kingdom

Acknowledgements We would like to thank Mrs Preeti Pulgari for her assistance with the review.

Contributors All authors have made substantial contributions to the manuscript. JY: conception and design of the study. VP, RC, JD, JY: acquisition of data, analysis and interpretation of data. VP, RC, JD, JY: drafting the article or revising it critically for important intellectual content. VP, RC, JD, JY: final approval of the version to be submitted.

Funding This work was supported by the National Institute of Health Research (NIHR). JY is supported by NIHR Post-Doctoral Fellowship (PDF-2014-07-061).

Disclaimer The views expressed are those of the authors and not necessarily those of the NHS, the NIHR or the Department of Health.

Competing interests None declared.

Patient consent Not required.

Provenance and peer review Not commissioned; externally peer reviewed.

Data sharing statement There are no unpublished data from this review.

Open access This is an open access article distributed in accordance with the Creative Commons Attribution Non Commercial (CC BY-NC 4.0) license, which permits others to distribute, remix, adapt, build upon this work non-commercially, and license their derivative works on different terms, provided the original work is properly cited, appropriate credit is given, any changes made indicated, and the use is non-commercial. See: http://creativecommons.org/licenses/by-nc/4.0/.

\section{REFERENCES}

1. National Institute for Health and Clinical Excellence. The management of hip fracture in adults. NICE Clin Guidel [CG124] 2011.

2. White SM, Griffiths R. Projected incidence of proximal femoral fracture in England: a report from the NHS Hip Fracture Anaesthesia Network (HIPFAN). Injury 2011;42:1230-3.

3. Urwin SC, Parker MJ, Griffiths R. General versus regional anaesthesia for hip fracture surgery: a meta-analysis of randomized trials. Br J Anaesth 2000;84:450-5.
4. White SM, Moppett IK, Griffiths R. Outcome by mode of anaesthesia for hip fracture surgery. An observational audit of 65535 patients in a national dataset. Anaesthesia 2014;69:224-30.

5. Parker MJ, Handoll HH, Griffiths R. Anaesthesia for hip fracture surgery in adults. Cochrane Database Syst Rev 2004:CD000521.

6. National Institute for Health and Clinical Excellence. Delirium: diagnosis, prevention and management. NICE Clin Guidel 2010.

7. American Psychiatric Association. Diagnostic and statistical manual of mental disorders. 5, 2013.

8. Dolan MM, Hawkes WG, Zimmerman SI, et al. Delirium on hospital admission in aged hip fracture patients: prediction of mortality and 2-year functional outcomes. J Gerontol A Biol Sci Med Sci 2000;55:M527-34.

9. Scottish Intercollegiate Guidelines Network. Management of hip fracture in older people, 2009.

10. Witlox J, Eurelings LS, de Jonghe JF, et al. Delirium in elderly patients and the risk of postdischarge mortality, institutionalization, and dementia: a meta-analysis. JAMA 2010;304:443-51.

11. Inouye SK, Westendorp RG, Saczynski JS. Delirium in elderly people. Lancet 2014;383:911-22.

12. Cole MG, Bailey R, Bonnycastle M, et al. Partial and no recovery from delirium in older hospitalized adults: frequency and baseline risk factors. J Am Geriatr Soc 2015;63:2340-8.

13. Cole MG, Mccusker J. Delirium in older adults: a chronic cognitive disorder? Int Psychogeriatr 2016;28:1229-33.

14. George J, Bleasdale S, Singleton SJ. Causes and prognosis of delirium in elderly patients admitted to a district general hospital. Age Ageing 1997;26:423-7.

15. Marcantonio ER, Flacker JM, Wright RJ, et al. Reducing delirium after hip fracture: a randomized trial. J Am Geriatr Soc 2001;49:516-22.

16. Vidán M, Serra JA, Moreno C, et al. Efficacy of a comprehensive geriatric intervention in older patients hospitalized for hip fracture: a randomized, controlled trial. J Am Geriatr Soc 2005;53:1476-82.

17. Lundström M, Olofsson B, Stenvall M, et al. Postoperative delirium in old patients with femoral neck fracture: a randomized intervention study. Aging Clin Exp Res 2007;19:178-86.

18. Bjorkelund KB, Hommel A, Thorngren KG, et al. Reducing delirium in elderly patients with hip fracture: a multi-factorial intervention study. Acta Anaesthesiol Scand 2010;54:678-88.

19. Griffiths R, Alper J, Beckingsale A, et al. Management of proximal femoral fractures 2011. Anaesthesia 2012;67:85-98.

20. Neuman MD, Silber JH, Elkassabany NM, et al. Comparative effectiveness of regional versus general anesthesia for hip fracture surgery in adults. Anesthesiology 2012;117:72-92.

21. Le-Wendling L, Bihorac A, Baslanti TO, et al. Regional anesthesia as compared with general anesthesia for surgery in geriatric patients with hip fracture: does it decrease morbidity, mortality, and health care costs? Results of a single-centered study. Pain Med 2012;13:948-56.

22. Luger TJ, Kammerlander C, Gosch M, et al. Neuroaxial versus general anaesthesia in geriatric patients for hip fracture surgery: does it matter? Osteoporos Int 2010;21:555-72.

23. Zhang H, Lu Y, Liu M, et al. Strategies for prevention of postoperative delirium: a systematic review and meta-analysis of randomized trials. Crit Care 2013;17:R47.

24. Guay J, Parker MJ, Gajendragadkar PR, et al. Anaesthesia for hip fracture surgery in adults. Cochrane Database Syst Rev 2016;2:CD000521.

25. Mason SE, Noel-Storr A, Ritchie CW. The impact of general and regional anesthesia on the incidence of post-operative cognitive dysfunction and post-operative delirium: a systematic review with meta-analysis. J Alzheimers Dis 2010;22 Suppl 3:S67-79.

26. Abou-Setta AM, Beaupre LA, Rashiq S, et al. Comparative effectiveness of pain management interventions for hip fracture: a systematic review. Ann Intern Med 2011;155:234-45.

27. Yeung J, Patel V, Champaneria R, et al. Regional versus general anaesthesia in elderly patients undergoing surgery for hip fracture: protocol for a systematic review. Syst Rev 2016;5:66.

28. Shamseer L, Moher D, Clarke M, et al. the PRISMA-P Group. Preferred reporting items for systematic review and meta-analysis protocols (PRISMA-P) 2015: elaboration and explanation. BMJ 2015;349:97647.

29. Higgins JP, Altman DG, Gøtzsche PC, et al. Cochrane Bias Methods GroupCochrane Statistical Methods Group. The Cochrane Collaboration's tool for assessing risk of bias in randomised trials. BMJ 2011;343:d5928.

30. Wells GA, Shea B, O'Connell D, et al. The Newcastle-Ottawa Scale (NOS) for assessing the quality of nonrandomised studies in meta-analyses. http://www.ohri.ca/programs/clinical_epidemiology/ nosgen.pdf (Accessed 1 Apr 2016). 
31. Atay T, Gukce Ceylan B, Ozmeric A, et al. The effects of related factors on one- and two-year mortality after a hip fracture in elderly Turkish patients. Trak Univ Tip Fak Derg 2010;27:127-31.

32. Saricaoglu F, Akinci SB, Atay S, et al. The effects of anesthesia techniques on postoperative mortality in elderly geriatic patients operated for femoral fractures. Turk Geriatr Derg 2012;15:434-8.

33. Duramaz A, Sarı C, Bilgili MG, et al. Outcomes of four different surgical techniques in the treatment of geriatric intertrochanteric femur fractures. Haseki Tıp Bülteni 2014;52:256-61.

34. Bennett-Guerrero E, Welsby I, Dunn TJ, et al. The use of a postoperative morbidity survey to evaluate patients with prolonged hospitalization after routine, moderate-risk, elective surgery. Anesth Analg 1999;89:514-9.

35. Bigler D, Adelhøj B, Petring OU, et al. Mental function and morbidity after acute hip surgery during spinal and general anaesthesia. Anaesthesia 1985;40:672-6.

36. Casati A, Aldegheri G, Vinciguerra E, et al. Randomized comparison between sevoflurane anaesthesia and unilateral spinal anaesthesia in elderly patients undergoing orthopaedic surgery. Eur $J$ Anaesthesiol 2003;20:640-6.

37. Kamitani K, Higuchi A, Asahi T, et al. [Postoperative delirium after general anesthesia vs. spinal anesthesia in geriatric patients]. Masui 2003;52:972-5.

38. Parker MJ, Griffiths R. General versus regional anaesthesia for hip fractures. A pilot randomised controlled trial of 322 patients. Injury 2015;46:1562-6.

39. Neuman MD, Mehta S, Bannister ER, et al. Pilot randomized controlled trial of spinal versus general anesthesia for hip fracture surgery. J Am Geriatr Soc 2016;64:2604-6.

40. Atay IM, Aslan A, Atay T, et al. risk factors and cognitive functions in elderly hip fracture patients with general and spinal anesthesia. Turk Geriatr Derg 2012;15:273-8.

41. Bitsch MS, Foss NB, Kristensen BB, et al. Acute cognitive dysfunction after hip fracture: frequency and risk factors in an optimized, multimodal, rehabilitation program. Acta Anaesthesiol Scand 2006;50:428-36.

42. Gilbert TB, Hawkes WG, Hebel JR, et al. Spinal anesthesia versus general anesthesia for hip fracture repair: a longitudinal observation of 741 elderly patients during 2-year follow-up. Am J Orthop 2000;29:25-35.

43. Ilango S, Bell RC, Bell J, et al. General versus spinal anaesthesia and postoperative delirium in an orthogeriatric population. Australas $J$ Ageing 2015.

44. Juliebø V, Bjøro K, Krogseth M, et al. Risk factors for preoperative and postoperative delirium in elderly patients with hip fracture. J Am Geriatr Soc 2009;57:1354-61.

45. Koval KJ, Aharonoff GB, Rosenberg AD, et al. Hip fracture in the elderly: the effect of anesthetic technique. Orthopedics 1999;22:31-4.

46. Mohamed M. Effectiveness of postoperative pain management in hip fractures: a multi centre audit of current practice. Reg Anesth Pain Med 2017;42(Supplement 1):e74.

47. Ojeda J. Choosing wisely: Perhaps general anesthesia is not the safest option for hip fracture elderly patients. J Am Geriatr Soc 2018;66(Supplement 2):S311.

48. Konttinen N, Rosenberg PH. Outcome after anaesthesia and emergency surgery in patients over 100 years old. Acta Anaesthesiol Scand 2006;50:283-9.

49. Luger MF, Müller S, Kammerlander C, et al. Predictors of postoperative cognitive decline in very old patients with hip fracture: a retrospective analysis. Geriatr Orthop Surg Rehabil 2014:5:165-72.

50. Michael A, Wharton C, Nightingale PG. Cognitive function and postoperative cognitive decline in hip fracture patients. J Am Geriatr Soc 2014:62:S87.

51. Shih Y-J, Hsieh C-H, Kang T-W, et al. General versus spinal anesthesia: which is a risk factor for octogenarian hip fracture repair patients? Int J Gerontol 2010;4:37-42.

52. O'Hara DA, Duff A, Berlin JA, et al. The effect of anesthetic technique on postoperative outcomes in hip fracture repair. Anesthesiology 2000;92:947-57.

53. Bellelli G, Mazzola P, Corsi M, et al. Anesthesia and post-operative delirium in elderly patients undergoing hip fracture surgery. Eur Geriatr Med 2013;4:S17-S18.

54. Kim SD, Park SJ, Lee DH, et al. Risk factors of morbidity and mortality following hip fracture surgery. Korean $J$ Anesthesiol 2013;64:505-10.

55. Choi YH, Kim DH, Kim TY, et al. Early postoperative delirium after hemiarthroplasty in elderly patients aged over 70 years with displaced femoral neck fracture. Clin Interv Aging 2017:12:1835-42.
56. Karaman Ö, Özkazanlı G, Orak MM, et al. Factors affecting postoperative mortality in patients older than 65 years undergoing surgery for hip fracture. Ulus Travma Acil Cerrahi Derg 2015;21:44-50.

57. Parvez K, Qureshi S, Ahmed I. Does anaesthetic technique influence postoperative ambulation after hip fracture? Anaesthesia 2010;65:1054.

58. Sutcliffe AJ, Parker M. Mortality after spinal and general anaesthesia for surgical fixation of hip fractures. Anaesthesia 1994:49:237-40.

59. Withey C, Morris R, Beech R, et al. Outcome following fractured neck of femur-variation in acute hospital care or case mix? $J$ Public Health Med 1995;17:429-37.

60. Zhao P, Lian X, Dou X, et al. Intertrochanteric hip fracture surgery in Chinese: risk factors for predicting mortality. Int J Clin Exp Med 2015;8:2789-93.

61. McElwaine JP, Curtin J, O'Brien R. Fractures of the neck of the femur. A prospective study of the early results. Ir J Med Sci 1980;149:457-64.

62. Dzupa V, Bartonícek J, Skála-Rosenbaum J, et al. [Mortality in patients with proximal femoral fractures during the first year after the injury]. Acta Chir Orthop Traumatol Cech 2002;69:39-44.

63. Kopp L, Edelmann K, Obruba P, et al. Mortality risk factors in the elderly with proximal femoral fracture treated surgically. [Czech]. Acta Chir Orthop Traumatol Cech 2009;76:41-6.

64. Bell JJ, Pulle RC, Crouch AM, et al. Impact of malnutrition on 12-month mortality following acute hip fracture. ANZ J Surg 2016;8686:157-61.

65. Maia D. In-hospital mortality in proximal femoral fracture surgery-does type of anesthesia matter? Reg Anesth Pain Med 2016;41:e34.

66. Al-Omran A, Sadat-Ali M. Is early mortality related to timing of surgery after fracture femur in the elderly? Saudi Med $J$ 2006;27:507-10.

67. Casaletto JA, Gatt R. Post-operative mortality related to waiting time for hip fracture surgery. Injury 2004;35:114-20.

68. Chu CC, Weng SF, Chen KT, et al. Propensity score-matched comparison of postoperative adverse outcomes between geriatric patients given a general or a neuraxial anesthetic for hip surgery: a population-based study. Anesthesiology 2015;123:136-47.

69. Fields AC, Dieterich JD, Buterbaugh K, et al. Short-term complications in hip fracture surgery using spinal versus general anaesthesia. Injury 2015;46:719-23.

70. Haider S, Clayton M, Hearn A, et al. Anaesthetic technique and mortality for hip fracture surgery in the over 90s. Anaesthesia 2010;65:1055-6.

71. Hekimoglu Sahin S, Heybeli N, Colak A, et al. Comparison of different anesthetic techniques on postoperative outcomes in elderly patients with hip fracture. Turkiye Klinikleri Journal of Medical Sciences 2012;32:623-9.

72. Holt G, Smith R, Duncan K, et al. Early mortality after surgical fixation of hip fractures in the elderly: an analysis of data from the Scottish Hip Fracture Audit. J Bone Joint Surg $\mathrm{Br}$ 2008;90:1357-63.

73. Karaca $\mathrm{S}$, Ayhan $\mathrm{E}$, Kesmezacar $\mathrm{H}$, et al. Hip fracture mortality: is it affected by anesthesia techniques? Anesthesiol Res Pract 2012;2012:1-5.

74. Kesmezacar H, Ayhan E, Unlu MC, et al. Predictors of mortality in elderly patients with an intertrochanteric or a femoral neck fracture. J Trauma 2010;68:153-8.

75. Liu JL, Wang XL, Gong MW, et al. Comparative outcomes of peripheral nerve blocks versus general anesthesia for hip fractures in geriatric Chinese patients. Patient Prefer Adherence 2014;8:651-9.

76. Li SG, Sun TS, Liu Z, et al. Factors influencing postoperative mortality one year after surgery for hip fracture in Chinese elderly population. Chin Med J 2013;126:2715-9.

77. Patorno E, Neuman MD, Schneeweiss S, et al. Comparative safety of anesthetic type for hip fracture surgery in adults: retrospective cohort study. BMJ 2014;348:g4022.

78. Neuman MD, Rosenbaum PR, Ludwig JM, et al. mortality, and length of stay after hip fracture surgery. JAMA 2014;311:2508-17.

79. Radcliff TA, Henderson WG, Stoner TJ, et al. Patient risk factors, operative care, and outcomes among older communitydwelling male veterans with hip fracture. J Bone Joint Surg Am 2008;90:34-42.

80. Rashid RH, Shah AA, Shakoor A, et al. Hip fracture surgery: does type of anesthesia matter? Biomed Res Int 2013;2013:1-5.

81. Seitz DP, Gill SS, Bell CM, et al. Postoperative medical complications associated with anesthesia in older adults with dementia. J Am Geriatr Soc 2014;62:2102-9. 
82. Sykora V, Novicka J. [Comparison of general and epidural anesthesia in femoral fractures in persons over 60]. Rozhl V Chir 1988;67:94-8.

83. Wood RJ, White SM. Anaesthesia for 1131 patients undergoing proximal femoral fracture repair: a retrospective, observational study of effects on blood pressure, fluid administration and perioperative anaemia. Anaesthesia 2011;66:1017-22.

84. Chia PH, Gualano L, Wong SY. Audit of patients admitted with fractured neck of femur. Anaesth Intensive Care 2012;40:1060-1.

85. Lund CA, Møller AM, Wetterslev J, et al. Organizational factors and long-term mortality after hip fracture surgery. A cohort study of 6143 consecutive patients undergoing hip fracture surgery. PLOS One 2014;9:e99308.

86. Eiskjaer S, Ostgard SE. Risk factors influencing mortality after bipolar hemiarthroplasty in the treatment of fracture of the femoral neck. Clin Orthop Relat Res 1991;270:295-300.

87. Garcia T, Rebelo H, Oliveira R, et al. Determinants of mortality in femoral neck fractures treated surgically. Eur J Anaesthesiol 2011;28:7.

88. Maheshwari R, Acharya M, Monda M, et al. Factors influencing mortality in patients on antiplatelet agents presenting with proximal femoral fractures. J Orthop Surg 2011;19:314-6.

89. Sangkomkamhang T, Sangkomkamhang US. Mortality risk factors in the elderly with fracture around hip treated surgically. Osteoporos Int 2013;1:S350-1.

90. Sangkomkamhang T, Swadpanich Sangkomkamhang U. Mortality rate and risk factor of patients with fragile hip fracture. Osteoporos Int 2014;25:S331.

91. Ratnarajah G, Chong K, Saifan C, et al. Outcomes after regional versus general anesthesia for hip fracture surgery in patients ages 90 years and above. J Am Geriatr Soc 2012;60:S145-S146.

92. McLeod K, Brodie MP, Fahey PP, et al. Long-term survival of surgically treated hip fracture in an Australian regional hospital. Anaesth Intensive Care 2005;33:749-55.

93. Moore J, Strock N, Kamat A. A survey of emergency hip fracture analgesia and morbidity/mortality at Aberdeen Royal Infirmary. Anaesthesia 2011:66:42.

94. Toukalkova M, Stourac P, Smekalova O, et al. Does an independent predictor of in-hospital mortality exist for patients with isolated proximal femoral fracture? A retrospective two-year observational study. [Czech]. Acta Chir Orthop Traumatol Cech 2015;82:288-92.

95. Basques BA, Bohl DD, Golinvaux NS, et al. General versus spinal anaesthesia for patients aged 70 years and older with a fracture of the hip. Bone Joint J 2015;97-B:689-95.

96. Whiting PS, Molina CS, Greenberg SE, et al. Regional anaesthesia for hip fracture surgery is associated with significantly more perioperative complications compared with general anaesthesia. Int Orthop 2015;39:1321-7.

97. Ercin E, Bilgili MG, Sari C, et al. Risk factors for mortality in geriatric hip fractures: a compressional study of different surgical procedures in 785 consecutive patients. Eur J Orthop Surg Traumatol 2017;27:101-6.

98. Nishi T. Comparative effectiveness of anesthesia technique among older patients after hip fracture surgery. Pharmacoepidemiol Drug Saf 2017;26:358-9.

99. Quu C, Chan PH, Zohman GL, et al. Impact of anesthesia on hospital mortality and morbidities in geriatric patients following emergency hip fracture surgery. J Orthop Trauma 2018;32:116-23.

100. Kilci O, Un C, Sacan O, et al. Postoperative mortality after hip fracture surgery: a 3 years follow up. PLoS One 2016;11:e0162097.

101. Naja Z, el Hassan MJ, Khatib H, et al. Combined sciaticparavertebral nerve block vs. general anaesthesia for fractured hip of the elderly. Middle East J Anaesthesiol 2000;15:559-68.

102. White SM, Moppett IK, Griffiths R, et al. Secondary analysis of outcomes after 11,085 hip fracture operations from the prospective UK Anaesthesia Sprint Audit of Practice (ASAP-2). Anaesthesia 2016:71:506-14.

103. Ahmed I, Khan MA, Allgar V, Ahmed I. Influence of anaesthesia on mobilisation following hip fracture surgery: an observational study. Journal of Orthopaedics, Trauma and Rehabilitation 2017;22:41-7.

104. Tung YC, Hsu YH, Chang GM. The effect of anesthetic type on outcomes of hip fracture surgery: a nationwide population-based study. Medicine 2016;95:e3296.

105. Fukuda T, Imai S, Nakadera M, et al. Postoperative daily living activities of geriatric patients administered general or spinal anesthesia for hip fracture surgery: a retrospective cohort study. $J$ Orthop Surg 2018;26:230949901775410-9.
106. Messina A, Frassanito L, Colombo D, et al. Hemodynamic changes associated with spinal and general anesthesia for hip fracture surgery in severe ASA III elderly population: a pilot trial. Minerva Anestesiol 2013;79:1021-9.

107. Baumgarten M, Rich SE, Shardell MD, et al. Care-related risk factors for hospital-acquired pressure ulcers in elderly adults with hip fracture. J Am Geriatr Soc 2012;60:277-83.

108. Maia D, Pereira N, Rebelo H. Intraoperative hypotension-the influence of different types of anesthesia in urgent orthopedic surgery. Reg Anesth Pain Med 2014;1:e199.

109. Minville V, Asehnoune K, Delussy A, et al. Hypotension during surgery for femoral neck fracture in elderly patients: effect of anaesthetic techniques. A retrospective study. Minerva Anestesiol 2008;74:691-6.

110. Gadsden J. Anesthetic technique and hypotension during hip fracture repair: a retrospective study of 2916 patients. 41st Annu Reg Anesthesiol Acute Pain Med Meet Am Soc Reg Anesth Pain Med ASRA 2016;41.

111. Haghighi M, Sedighinejad A, Nabi BN, et al. Is spinal anesthesia with low dose lidocaine better than sevoflorane anesthesia in patients undergoing hip fracture surgery. Arch Bone Jt Surg 2017:5:226-30.

112. Dubljanin-Raspopović E, Marković-Denić L, Ivković K, et al. The impact of postoperative pain on early ambulation after hip fracture. Acta Chir lugos/ 2013;60:61-4.

113. Kamel HK, lqbal MA, Mogallapu R, et al. Time to ambulation after hip fracture surgery: relation to hospitalization outcomes. J Gerontol A Biol Sci Med Sci 2003;58:M1042-5.

114. Sathiyakumar V, Thakore R, Greenberg SE, et al. Risk factors for discharge to rehabilitation among hip fracture patients. Am J Orthop 2015;44:E438-43

115. World Health Organisation. The ICD-10 Classification of Mental Behavioural Disorders-diagnostic criteria for research, 1993.

116. Marcantonio ER. Clinical management and prevention of delirium. Psychiatry 2008;7:42-8.

117. Neelon VJ, Champagne MT, Carlson JR, et al. The NEECHAM Confusion Scale: construction, validation, and clinical testing. Nurs Res 1996:45:324-30.

118. Bellelli G, Morandi A, Davis DH, et al. Validation of the 4AT, a new instrument for rapid delirium screening: a study in 234 hospitalised older people. Age Ageing 2014;43:496-502.

119. Society BG. Guidelines for the prevention diagnosis and management of delirium in older people in hospital. 2006.

120. Hendry K, Quinn TJ, Evans J, et al. Evaluation of delirium screening tools in geriatric medical inpatients: a diagnostic test accuracy study. Age Ageing 2016;45:832-7.

121. Deiner S, Silverstein JH. Postoperative delirium and cognitive dysfunction. Br J Anaesth 2009;103(Suppl 1):i41-i46.

122. Brauer C, Morrison RS, Silberzweig SB, et al. The cause of delirium in patients with hip fracture. Arch Intern Med 2000;160:1856-60.

123. .Saczynski JS, Marcantonio ER, Quach L, et al. Cognitive trajectories after postoperative delirium. N Engl J Med 2012;367:30-9.

124. Litaker D, Locala J, Franco K, et al. Preoperative risk factors for postoperative delirium. Gen Hosp Psychiatry 2001;23:84-9.

125. Inouye SK. Delirium in older persons. N Engl J Med 2006;354:1157-65.

126. Marcantonio ER, Goldman L, Orav EJ, et al. The association of intraoperative factors with the development of postoperative delirium. Am J Med 1998;105:380-4.

127. Fong HK, Sands LP, Leung JM. The role of postoperative analgesia in delirium and cognitive decline in elderly patients: a systematic review. Anesth Analg 2006;102:1255-66.

128. Alagiakrishnan $\mathrm{K}$, Wiens $\mathrm{CA}$. An approach to drug induced delirium in the elderly. Postgrad Med $J$ 2004:80:388-93.

129. Griffiths R, Mehta M. Frailty and anaesthesia: what we need to know. Continuing Education in Anaesthesia Critical Care \& Pain 2014:14:273-7.

130. Dodds C, Foo I, Jones K, et al. Peri-operative care of elderly patients - an urgent need for change: a consensus statement to provide guidance for specialist and non-specialist anaesthetists. Perioper Med 2013;2:6.

131. Aldecoa C, Bettelli G, Bilotta F, et al. European Society of Anaesthesiology evidence-based and consensus-based guideline on postoperative delirium. Eur J Anaesthesiol 2017;34:192-214. 